Especial: Naturaleza amena y naturaleza agreste en las letras hispánicas

\title{
Atacama: el desierto salitroso como tema literario en Hernán Rivera Letelier
}

\author{
Marta Piña Zentella \\ Universidad Autónoma de Baja California Sur, México \\ mpina@uabcs.mx \\ https://orcid.org/0000-0001-9440-6367
}

Recibido: 5 de marzo 2018

Aceptado: 20 de mayo 2018

\section{Resumen:}

A lo largo de su obra narrativa Hernán Rivera Letelier (Talca, Chile, 1950) describe la vida en el Norte Grande de Chile, específicamente en el desierto de Atacama durante varias décadas del siglo XX. El tema de las salitreras de Atacama explica el mundo de la gente que no conoce otra forma de vida, si bien las oficinas y los campamentos pueden emular un estilo urbano impostado en su arquitectura y en su operar cotidiano, el destino de los pobladores y su cosmovisión es de aislamiento. Sin embargo, los mineros asentados con sus familias en esa zona desértica han aprendido a sobrevivir en condiciones extremas y, desde la fórmula literaria que presenta el autor, la adaptación se logra incluso bajo una especie de sana resignación que los motiva a disfrutar el ocio. La constante que prevalece en la narrativa de Rivera es la desolación del espacio geográfico y la inclemencia del clima.

Palabras clave: Narrativa de Rivera Letelier, Desierto de Atacama, oficinas salitreras, Gran Norte chileno.

\section{Atacama: the salty desert as a literary theme in Hernán Rivera Letelier}

\section{Abstract:}

Throughout his work, Hernán Rivera Letelier (Talca, Chile, 1950) describes the life in the Great North of Chile in the course of several decades of the XXth century, specifically in the Desert of Atacama. The world in Atacama's nitrate fields is the world of the people that do not know another way of life, even though the offices

\section{(c) (i) (2)(2)}

La Revista Estudios es editada por la Universidad de Costa Rica y se distribuye bajo una Licencia Creative Commons Atribución-NoComercial-CompartirIgual 3.0 Costa Rica. Para más información envíe un mensaje a 
Especial: Naturaleza amena y naturaleza agreste en las letras hispánicas

and the camps may emulate an urban style based upon their architecture and their daily management, the destiny and worldview of the people is of isolation. However, the miners settled with their families on this region have learned to live in extreme conditions and, considering the literary device used by the author, their adaptation even comes with a sort of healthy resignation for the free time. The common theme throughout Rivera's narrative work is the desolation and loneliness at that specific geographical space.

Keywords: Rivera Letelier's narrative, Atacama Desert, saltpeter office, Gran Norte from Chile.

-El desierto es bello- añadió el Principito.

-Eso es verdad. Yo siempre he amado el desierto. Uno puede sentarse sobre una duna de arena sin ver ni escuchar nada. Y, sin embargo, siempre hay algo que brilla en el silencio.

\section{Exupéry}

A. de Saint-

Si la pampa bajo el sol de mediodía es algo alucinante, de noche se vuelve fantasmal y misteriosa. $Y$ esa transfiguración se hace sensible y evidente sobre todo en las noches de luna. $Y$ aquella noche aventurera la luna nacía grande, grávida, magnética. Al contemplar aquella grandiosidad sobrecogedora de la pampa, iluminada por una luna sonámbula que ella nunca había advertido tan cerca ni tan sobrenatural, la Pan con Queso sintió un vago estremecimiento de pavor; simplemente se le encogió el corazón. De niña le había tenido terror a la soledad y eso que se veía delante suyo, extenso, silencioso, latente, no era ni más ni menos que el propio planeta de la soledad.

LRCR Hernán Rivera Letelier

Hernán Rivera Letelier' es originario en Talca, Chile, nació el 11 de julio de 1950.

Proveniente de una familia humilde que se mantiene gracias al trabajo del padre

\section{(C) $\odot \Theta \odot$}

La Revista Estudios es editada por la Universidad de Costa Rica y se distribuye bajo una Licencia Creative Commons Atribución-NoComercial-CompartirIgual 3.0 Costa Rica. Para más información envíe un mensaje a 
Especial: Naturaleza amena y naturaleza agreste en las letras hispánicas en las minas de salitre, se crió y vivió en Algorta. A los siete años entró a la escuela, es aquí donde se da el "el milagro", como lo califica Letelier, de aprender a leer. Quedó fascinado con dos poemas que relee y relee, sin saber muy bien por qué: Rabindranath Tagore y el poema "Vagón de tercera" de Antonio Machado. Serían el germen de su pasión por la literatura y la convicción de ser escritor. A los once años junto con su familia se trasladó a Antofagasta, donde murió su madre por la picadura de la araña del rincón ${ }^{i i}$. A partir de esa situación vivió en el patio trasero de una iglesia evangélica; realizando múltiples oficios para sobrevivir: vendedor de diarios, mensajero, electricista.

A los catorce años viajó a la pampa, donde se desempeñó como mensajero en Anglo Lautaro, actualmente Soquimich iii. A los dieciocho años viajó por distintos países sudamericanos (Argentina, Chile, Bolivia y Ecuador) viaje en el que se reencuentra con la promesa de llegar a ser escritor.

En 1973 regresó a Antofagasta: trabaja en la salitrera Mantos Blancos. Un año después se casó con María Soledad Pérez, de 17 años. Partieron a la salitrera Pedro de Valdiviaiv. Ahí reinicia sus estudios en la escuela nocturna, cursa séptimo y octavo año. En Inacap obtiene la licenciatura de enseñanza media. Trabajó en las minas por más de una década. En 1994 publica La reina Isabel cantaba rancheras y de ahí, hasta la fecha, las novelas han sido constantes. No obstante, los tres títulos más recientes forman parte de una trilogía detectivesca, es decir, se aprecia ya un cambio temático en la trayectoria del autor ${ }^{v}$.

El eje reiterativo sobre el cual se expande la trama de una obra narrativa 0 una suma de obras durante dos décadas (de 1994 a 2014) es, sin duda, el Desierto de Atacama de forma general; y algunas de las oficinas de manera particular: Desolación, Pampa Unión, Santa María de Iquique, Coya Sur, entre otras.

\section{(c) (i) (2)}

La Revista Estudios es editada por la Universidad de Costa Rica y se distribuye bajo una Licencia Creative Commons Atribución-NoComercial-CompartirIgual 3.0 Costa Rica. Para más información envíe un mensaje a 
Especial: Naturaleza amena y naturaleza agreste en las letras hispánicas

Siguiendo a Boris Tomashevsky el tema resulta de la una unidad compuesta de pequeños elementos temáticos, dispuestos en una relación determinada. En la disposición de estos elementos temáticos, se observan dos tipos principales: 1) un nexo causal-temporal que liga el material temático; 2) los hechos son narrados como simultáneos, o en una diversa sucesión de los temas, sin un nexo causal interno. vi Al considerar una docena de novelas de Rivera Letelier escritas en el marco de dos décadas, se confirma que el concepto tema narrativo como categoría propia de la obra -más que como objeto externo a ésta- se cumple en la praxis escritural del chileno cual nexo causal-temporal pero también por los hechos narrados bajo un parámetro de simultaneidad espacial.

El aporte cultural, social y literario de Rivera Letelier sustentado en la obra narrativa cuyo tema general es la cotidianeidad en las oficinas salitreras consiste, justamente, en la revalorización de la vida de los habitantes pampinos en el norte chileno y su adaptación concertada al medio, en aras de rescatar tanto un modelo de vida de antaño, como reforzar la exclusividad de la naturaleza desértica cual patrimonio nacional chileno.

Dentro de su ficción narrativa es notoria la voluntad por parte de hombres y mujeres de realizar su vida en torno a la praxis cotidiana de ser un todo orgánico junto con el medio ambiente, a pesar de que la naturaleza en esas coordenadas geográficas sea hostil, compleja y árida. Los mineros y sus familias, de acuerdo al autor, hacen un esfuerzo continuo por aclimatarse y aprovechar al máximo las oportunidades (de vida, de trabajo, de entretenimiento) que ese desierto norteño les brinda.

El mundo en las salitreras de Atacamavii (norte de Chile) es el mundo de los trabajadores que vivieron en las oficinas o campamentos cuyas faenas se centraban en la extracción del salitre: "En agosto de 1866, don José Santos Ossa recibe la noticia de la existencia de salitre en la zona de Antofagasta, de labios de su hijo Alfredo y de los de Juan Zuleta y Martín Rojas. En el lugar donde se

\section{(c) (i) (2) (2)}

La Revista Estudios es editada por la Universidad de Costa Rica y se distribuye bajo una Licencia Creative Commons Atribución-NoComercial-CompartirIgual 3.0 Costa Rica. Para más información envíe un mensaje a 
Especial: Naturaleza amena y naturaleza agreste en las letras hispánicas descubrió el salitre se levantó la primera Oficina de esta región, la del Salar del Carmen." (Sabella: 11) En el momento de mayor auge de la explotación minera durante el paso del siglo XIX al siglo XX estuvieron en funciones 170 oficinas viii en el Norte Grande chileno, como lo llamó el poeta Andrés Sabella en obra homónima: Norte Grande. Novela del salitre (1944).

La gente que nació en las oficinas no conoce otra forma de vida, si bien las oficinas pueden emular un estilo urbano impostado en su disposición arquitectónica, en general son precarias y pobres; en su operar cotidiano, el destino de los pobladores y su cosmovisión es de aislamiento, de encierro y desencanto. Asegura la narradora de La contadora de películas (2009): "Nuestra Oficina era una de las más pobres del cantón. La gente no tenía qué ver ni qué hacer en las largas tardes pampinas. No había filarmónica donde ir a bailar, no contábamos con banda de música que tocara retretas los fines de semana en la plaza. Ni siquiera teníamos día de tren, que en las otras oficinas donde había estación ferroviaria era toda una fiesta. Sólo nos quedaba el cinematógrafo." ( $p$. 77) Los mineros asentados con sus familias en esa zona llevaron una existencia triste y dolorosa, víctimas de un anhelo de éxodo a veces imposible, se adaptaron al desierto y sobrevivir en él. Esa forma de encierro artificial pero obligatorio forjó un microcosmos muy interesante que a su vez creó una literatura particular que Rivera Letelier retoma como tema de una docena de novelas. Cito a Mauricio Ostria:

Sea por las dificultades sin cuenta que impone el desierto a la vida humana, o por el riesgo permanente que convierte la vida en aventura precaria; tal vez por la paradoja de la riqueza encerrada en la más absoluta aridez o por los conflictos personales o sociales que surgieron de la apetencia desmesurada; quizás por las nostalgias que el paisaje polvoriento desataba en los enganchados o en los fantasmas que poblaban la imaginación afiebradas de los tercos buscadores de tesoros; lo cierto es que la literatura nortina se 
Especial: Naturaleza amena y naturaleza agreste en las letras hispánicas

identificó prontamente con el desierto y el hombre del norte fue visto casi siempre como una emanación de ese universo de seca apariencia, pero de rico mundo interior. (2014, p. 38)

El autor de la reciente novela La muerte se desnuda en La Habana (2017) ha consolidado su mayor aporte a la literatura nacional con la recreación, descripción y rescate del modelo de vida en estas oficinas de la pampa chilena; si bien no es único que ha abordado el tema, su historia personal y su obra contienen algunos asombros dignos de enumerarse, como lo hace Alicia Llarena:

El caso del novelista Hernán Rivera Letelier no deja de resultar curioso y proveedor de asombros varios. Primero, porque este escritor autodidacta, originario de la VII Región del país, concretamente de Talca, fue hasta la publicación de su primera novela uno de los tantos mineros en las célebres salitreras del norte de Chile. Segundo, porque en poco tiempo consiguió el reconocimiento de sus congéneres (obtuvo dos veces el Premio del Consejo Nacional de Literatura, en 1994 y1996), la traducción a más de cinco idiomas y preciados galardones intemacionales (la distinción "Chevalier des Artsel des Lettres" del Ministerio de Cultura en Francia y el premio de narrativa "Arzobispo Juan de San Clemente" a la mejor novela escrita en lengua española, otorgado en Galicia). Tercero, porque su narrativa es hoy en día un fenómeno social, hecho que evidencia la conversión en bestseller de algunos de sus textos, cuyas ediciones, en algunos casos, se agotaron incluso antes de haber sido puestas a la venta. $Y$ cuarto, porque en las novelas publicadas hasta la fecha convergen las formas $e$ intenciones del nuevo regionalismo hispanoamericano, reflotando para la historia chilena una geografía literaria cuyo peso en la historia real del país es de suma importancia. (2007, pp.167-168).

Y puede añadirse, entre otros aspectos a destacar, porque escribe una prosa de simultaneidades temáticas amparadas bajo una configuración espacial determinada que soporta esos mundos imaginarios casi imposibles pero sólidos a

La Revista Estudios es editada por la Universidad de Costa Rica y se distribuye bajo una Licencia Creative Commons Atribución-NoComercial-CompartirIgual 3.0 Costa Rica. Para más información envíe un mensaje a revistaestudios.eeg@ucr.ac.cr. 
Especial: Naturaleza amena y naturaleza agreste en las letras hispánicas los cuales, los lectores hispanoamericanos están acostumbrados. Mundos donde se superponen historias personales encima del destino común, como en el tren Longitudinal (el Longinos), ferrocarril que cruzaba varias regiones chilenas y servía de enorme columna vertebral entre las oficinas desplegadas por cientos de kilómetros:

En esos momentos el tren cruza por un infinito páramo de arenas blancas. Un mundo alucinante se despliega a cada lado del vagón, un mundo en donde la sombra no existe y las piedras parecen a punto de estallar por lo ardiente y luminoso del aire. $Y$ todo ese abrasamiento aún no es nada, piensa el acordeonista. $Y$ mirando de reojo a la madre madame Luvertina, que va sentada sola frente a él, le dice, guasón: <<Vamos entrando al infierno, abuelita >>. (Rivera, 2000, p. 120)

En la novela Los trenes se van al purgatorio (2000), los viajeros están atrapados y el tren figura como un submundo o microcosmos donde se suceden un nacimiento, una muerte, una violación. Se alcanza el amor y el desamor, se despliegan la solidaridad, la alegría y el dolor; un mundo donde el lector se involucra con esa gran metáfora del rescate, de ver su realidad que es la lectura y la novela de acurdo con Julio Ortega ${ }^{\text {ix }}$ y se identifica con por lo menos algún pasajero o pasajera aunque nunca se haya subido al Longinos. Llarena habla de:

El resurgimiento de las literaturas regionales en las últimas décadas del siglo $X X$ - visibles y especial mente relevantes en países como Chile, Argentina y México- es sin duda uno de los fenómenos socio-culturales más atractivos e interesantes, en íntima relación con el auge delas periferias en el discurso posmoderno, con la consiguiente descentralización de la cultura, y con las lógicas tensiones entre la globalización y el localismo. De hecho, y aunque el antiguo inventario naturalista fue sustituido hace tiempo por el desarrollo de la narrativa urbana, psicológica, o enfocada en los problemas sociales de América Latina, proceso facilitado por el descrédito de los tópicos teluristas a los que ya hemos aludido, en las últimas décadas del siglo $\mathrm{XX}$ el espacio reapareció con

La Revista Estudios es editada por la Universidad de Costa Rica y se distribuye bajo una Licencia Creative Commons Atribución-NoComercial-CompartirIgual 3.0 Costa Rica. Para más información envíe un mensaje a 
Especial: Naturaleza amena y naturaleza agreste en las letras hispánicas

energía postulándose de nuevo como mecanismo de representación de la realidad y la identidad americanas. (2007, p.159).

El espacio narrativo de este autor es el desierto. Rivera Letelier o el "hijo del salitre", no se limita a formar parte de una nueva literatura nacional nortina o de insertarse en la tradición de los nuevos regionalismos, sino también logra alimentarse de otros autores anteriores cuyas obras cumplen la función de hipotextos diluidos, plenamente asimilados en sus novelas del y además convierte su experiencia individual a una pequeña epopeya gremial a través del rescate de la memoria colectiva, esa es otra de las claves de su exitosa narrativa. Su biografía es la de muchos, su éxito o fracaso no es individual sino pampino y, por ende, desde una perspectiva socio-económica, abarca un ámbito nacional. Desde una visión histórico-romántica el Volksgeist (J. G. Herder) o "espíritu popular", se revela en el arquetipo del minero cuyo destino social se fragua por su lugar de nacimiento, bajo la sombra de un determinismo insondable.

Una de esas novelas principales que nutren a Rivera Letelier es Norte Grande. Novela del salitre de Andrés Sabella, que refiere con gran lirismo y tono de lamento la vida en las oficinas, tono sometido, reflejo de la vulnerabilidad de los pobladores que sufren la naturaleza agreste. La deuda hacia la novela de Sabella es evidente. En esa primera versión donde se relata de manera fragmentada, la historia de los hombres del salitre y donde se describe dialécticamente la furia y la belleza de la naturaleza desértica, ya se perfilan los arquetipos que reaparecen en la prosa de Rivera: el minero, el viajero en busca de fortuna, el explotador, las mujeres de vida galante, el salteador, los dueños de la oficina, así como los lugares icónicos de las oficinas: el cinematógrafo, la fábrica de hielo, la escuela, la iglesia, las calles y otros igualmente representativos.

Medio siglo después de que Norte Grande. Novela del salitre, Rivera Letelier elige el mismo tema (como ya se ha escrito), pero cambia a un tono

\section{(C) $(0 \odot$}

La Revista Estudios es editada por la Universidad de Costa Rica y se distribuye bajo una Licencia Creative Commons Atribución-NoComercial-CompartirIgual 3.0 Costa Rica. Para más información envíe un mensaje a 
Especial: Naturaleza amena y naturaleza agreste en las letras hispánicas

proclive a lo festivo, a un discurso donde a pesar de la miseria y la desolación, se celebra la alegría de la vida (bailes, días de pago, concursos, futbol, celebraciones patrias, mujeres de vida galante, el arribo del Longinos cargado de misterios) en contraste con la soledad y la sequía perennes en la pampa desértica. Hernán Rivera cambia el locus agreste por un locus amoenus que permite objetivar de forma más realista la región geográfica que se ha tematizado, crea un paisaje que explota narrativamente un asunto filosófico ${ }^{x}$ : la relación del hombre con su entorno y gesta la concepción de un paisaje identitario que trasciende las fronteras espacio-temporales y alcanza a los lectores en potencia compartiendo un proceso o fenómeno de ambientalidad. Como lo muestran las siguientes citas:

Imagínense el cuadro: nada en el cielo — ni una nubecita expósita - y nada en la tierra -ni una brizna de mala hierba-; dividan estas dos nadas con una línea temblorosa - e imaginaria - llamada horizonte; añádanle un calor de caldera durante el día y un frío glacial por las noches. (Rivera, 2011, p. 103).

Y es que en esta parte del desierto, la tierra pertenece por completo al reino de los minerales. No existía flora ni fauna. Por lo tanto, aquí la soledad es absoluta, y el silencio, universal. $Y$ nada huele a nada. $O$ más bien todo huele a una sola cosa: a planeta. En estos territorios calcinados se siente el olor original del planeta. (Rivera: 2011, p. 87)

Algo no le cuadraba a la vista. Y no era la aspereza del paisaje, ni el vértigo de esos horizontes temblorosos, ni la transparencia desquiciante del aire. Había recorrido muchas veces las salitreras y eso era lo normal en estos parajes. Solo que nunca había estado en esta parte del desierto. Esto era el mismo purgatorio ¿Habría venido hasta aquí a purgar sus culpas? (Rivera: 2014, p. 44)

\section{(C) $(00$}

La Revista Estudios es editada por la Universidad de Costa Rica y se distribuye bajo una Licencia Creative Commons Atribución-NoComercial-CompartirIgual 3.0 Costa Rica. Para más información envíe un mensaje a 
Especial: Naturaleza amena y naturaleza agreste en las letras hispánicas

Así es el desierto de Atacama. Un calcinatorio. Visto desde un avión, su panorama resulta tan impresionante, su costurón de cerros tan pavorosamente árido, que da la impresión de una cicatriz de quemadura en la mejilla del globo terráqueo. Y todo ese desamparo, toda esa soledad planetaria, se hace más triste todavía por ese huesario de pueblos muertos que dejó la industria salitrera, diseminados a lo largo de sus mil kilómetros de extensión. (Rivera: 2011, p. 104)

Rivera Letelier llama a la pampa región con un "sol del carajo" llena de "polvo de mierda". Lorenzo Anabalón mira desde el tren (Los trenes se van al purgatorio, 2000) y piensa: "Afuera el mundo es un círculo ardiendo y él se queda sin despegar la vista de esos cerros color ocre, como fermentados por el calor." (27) Afuera el paisaje es para llorar de desolación. Y, por lo que se ve hacia adelante, no hay no para cuando llegar al pueblo más cercano." (Rivera, 2000, p. 31) o bien en La reina Isabel...: "La nube de polvo que día y noche emana de los molinos de caliche hace un lento viraje en cuarenta y cinco grados y, silenciosa y densa, orillando la gran torta de ripios, se va dejando caer sobre el dormido campamento." (Rivera, 2000, 194) [...] la polvareda va cubriendo completamente las calles, los árboles y la noche; apestando mórbidamente la luz de la luna llena; colándose al interior de las casas por todos los agujeros imaginables. [...] Imperceptible como una enfermedad, la nube de polvo se va cerniendo nocivamente sobre los seres y las cosas..." (Rivera, 2000, 194) "Y la pavorosa nube de tierra, el letal hongo de sílice, continúa precipitándose sobre el inerme campamento dormido [...] difuminando los contornos del mundo, eclipsando mortecinamente el duro universo del hombre salitrero" (Rivera, 2000, 195).

A pesar de la vida dura, resulta paradójico pensar que en las oficinas había espacio para la fiesta, la alegría como en Pampa Unión, para el regocijo (sobre todo carnal). Tal como asegura María Margarita la niña que cuenta películas. Cuando la oficina donde vivía quedó abandonada, convertida en pueblo fantasma, 
Especial: Naturaleza amena y naturaleza agreste en las letras hispánicas ella permaneció allí y llegaba gente citadina a mirar el lugar y preguntaban: "que cómo pudimos vivir en esos peladeros. El paisaje se les antoja poco menos que una provincia del infierno. Yo les respondo orgullosa que para nosotros era el Paraíso." (Rivera, 2000, 113) "Aquí nadie se moría de hambre. Nos ayudábamos unos a otros. Por las noches podíamos dormir con las puertas abiertas y no pasaba nada." (113). La misma idea se maneja Historia de amor con un hombre bailando (2013) "Además, en la pampa la gente era así por naturaleza; habitábamos el desierto más duro del planeta y para sobrevivir dependíamos uno del otro. La solidaridad, pues, era fundamental” (Rivera, 2013, p.18).

Aquí se puede aplicar la máxima garciamarquina: «Por fortuna, Macondo no es un lugar sino un estado de ánimo que le permite a uno ver lo que quiere ver, y verlo como quiere», palabras escritas por el autor en su aula escolar.

Uno de los aspectos más contrastantes en esta propuesta narrativa es justamente el impulso positivo que se ejerce en el tiempo libre o tiempo de ocio, ya que algunos de los protagonistas son quienes se desloman en las calicheras y otros, se dedican a ser poeta o músico o mentalista o enamorado, bailarín o futbolista. Claudio Maíz expone en un trabajo titulado: "La narrativa de Rivera Letelier. Los signos de la escasez y la abundancia compensatoria" que: "Rivera sitúa en un primer plano el placer, el ocio, los tiempos muertos para el trabajo." (p. 160)

Maíz anota que en: "un espacio no urbano, el trabajo como acción física, tangible y material ha desaparecido, a pesar de que exista una referencia al mismo, es de manera tan soslayada o tangencial que se hace imperceptible." (p. 160) Maíz anota que en las obras principales "hay una negación de la ética del trabajo capitalista", "el juego, el placer, el ocio se valorizan, pues, más que el trabajo." (p. 160)

\section{(c) (i) (2)}

La Revista Estudios es editada por la Universidad de Costa Rica y se distribuye bajo una Licencia Creative Commons Atribución-NoComercial-CompartirIgual 3.0 Costa Rica. Para más información envíe un mensaje a 
Especial: Naturaleza amena y naturaleza agreste en las letras hispánicas

La tesis que Claudio Maíz presenta respecto a este tema es la siguiente: el juego, el ocio y el placer cumplen la función de contrapeso social frente a la brutal realidad en la que viven los pobladores de las oficinas desérticas. La eficacia, la causa motriz de la maquinaria social no es el trabajo, Rivera Letelier invierte el modelo, no se trata de representar el trabajo arduo sino de comprender cómo los mineros sobreviven a esa explotación y a ese clima infernal. En buena medida el universo narrativo riveriano se sustenta en la oralidad y el humor. "La materia narrativa se abastece de la cultura oral, canalizando así, la expresión de una colectividad que ha valorizado el placer y el juego como una manera de contrapesar el inhumano trabajo minero a la que ha sido sometida." (p. 160) Agrega:

Lo que ha dejado de existir no son solo las salitreras, de hecho es un proceso cuyo comienzo se ubica en las primeras décadas del siglo XX, sino, y fundamentalmente, las organizaciones mancomunales; en otras palabras, no es la representación de la realidad histórica y social del norte salitrero lo que se compromete en las novelas, sino más bien la representación de la realidad de esas identificaciones imaginarias, a través de las cuales se ha "percibido", "vivido" y "sentido" esa realidad" (Maíz, 2002, p. 161).

Esta cita y este trabajo permiten plantear entonces el ocio como salvación, así como en otros casos el mito ha servido de referencia representativa, en el novelista chileno - de acurdo a Claudio Maíz- la búsqueda del tiempo perdido se centra en esas identificaciones del imaginario colectivo salvadas, rescatadas por el ocio, el juego y el placer. También se aprecia con este trabajo que la creación o la motivación creativa en Hernán Rivera Letelier es constante, mientras la escritura es más pausada, más pensada. La parte histórica de sus novelas puede -de igual modo- asimilarse como el proceso de adaptación de representaciones discursivas en un momento específico y en un lugar específico.

Desde mi perspectiva otra forma de equilibrar la forma de vida inhumana de los habitantes de las oficinas salitreras es justamente la percepción de la realidad

La Revista Estudios es editada por la Universidad de Costa Rica y se distribuye bajo una Licencia Creative Commons Atribución-NoComercial-CompartirIgual 3.0 Costa Rica. Para más información envíe un mensaje a 
Especial: Naturaleza amena y naturaleza agreste en las letras hispánicas a través de la fantasía, es decir, a través de mecanismos que no dejan percibir la realidad con claridad, con exactitud. Se percibe con ese toque de ilusión óptica o de alteración mental que propicia un estado de ánimo alterado o un estado de vida en condiciones extremas ya sea por factores físicos internos o externos (en la gente sana).

El mundo fantástico y fantasmagórico modela una forma de vida ilusoria que permite, aunque sea por momentos, soñar, desear, creer en un sistema más justo en una vida menos sufrida, como la niña Flor María de los Cielos durante la travesía en tren. Hay una conversión en la niña, Flor María pasa de ser una niña abusada, sucia, piojosa y harapienta a una criatura envuelta en un vestido blanco de primera comunión, peinada y que sonríe por primera vez en la travesía; esa conversión se da por la solidaridad de los viajeros, pero esa visión-ficción es irreal: "da la impresión a todos en el coche de que en realidad no es Flor de María de los Cielos, sino una aparición sobrenatural de ella misma." (Rivera, 2000, p.141).

Desde las primera páginas de La reina Isabel cantaba rancheras(1994) el viejo Fiosca busca compañía para dar una ronda fantasmal por las calles solas de la oficina; en realidad en el mundo narrativo de Rivera Letelier la oficina equivale a un pueblo fantasma y, por supuesto, nimbado de polvo. En esa misma novela el Poeta Mesana ha escrito su Cantata de las oficinas salitreras abandonadas que no es sino "una recopilación de más de doscientos nombres de esos fantasmas diseminados a través del desierto." (Rivera, 1994, p. 20) El rasgo fantasmagórico es una constante tal como se percibe, casi cuarenta años antes, en La hojarasca (1955). En un análisis amplio hay un grado de emulación, de hipertextualidad asimilada entre los funerales de la Reina Isabel y el cuento "Los funerales de la Mamá Grande" de García Márquez. (La fiesta, la exuberancia, la fama, la trascendencia de la noticia, la orfandad simbólica en que queda la comunidad, la pérdida de la matriarca, etc.)

\section{(c) (i) (2)}

La Revista Estudios es editada por la Universidad de Costa Rica y se distribuye bajo una Licencia Creative Commons Atribución-NoComercial-CompartirIgual 3.0 Costa Rica. Para más información envíe un mensaje a 
Especial: Naturaleza amena y naturaleza agreste en las letras hispánicas

Otras formas de representación del ámbito de la fantasía o fantasmal en las novelas de Rivera Letelier es el simple hecho de no ser quien uno es; la gente es nombrada por apodos, no responde a los nombres de pila, viven momentos de esparcimiento a través de canciones o películas contadas y recontadas, el dinero no es dinero, son fichas o vales para cambiar, es falso. La gente no olvida a los fantasmas de la matanza en la escuela de lquique; las mujeres viven una fantasía de abrir un Centro de mujeres y todo se presenta como difuminado por la cualidad de inasible. La costurera de El vendedor de pájaros tiene el temor de que el pueblo quede vacío y ella con su familia queden convertidos en "dolientes figuras de salitre" (Rivera, 2013, p. 107) a la intemperie, en mitad de la pampa, solos como estatuas del absurdo, como fantasmas de ellos mismos.

La propuesta literaria de Rivera Letelier como ejercicio de concientización que busca que un modelo de vida en un tiempo y un espacio determinados trascienda como fenómeno literario, social y nacional alcanza un estatus de representatividad en la obra completa de este autor. El tema del desierto pampino puede desplegarse, sin temor a equivocarme, de forma reiterada y sin perder su función de literatura comprometida que posee un estilo propio.

\section{(C) $(00$}

La Revista Estudios es editada por la Universidad de Costa Rica y se distribuye bajo una Licencia Creative Commons Atribución-NoComercial-CompartirIgual 3.0 Costa Rica. Para más información envíe un mensaje a 


\section{BIBLIOGRAFÍA}

Especial: Naturaleza amena y naturaleza agreste en las letras hispánicas

Rivera Letelier Hernán, (1994) La reina Isabel cantaba rancheras, Santiago: Planeta.

, (1996) Himno del ángel parado en una pata, Santiago: Planeta.

, (2000) Los trenes se van al Purgatorio, Santiago: Planeta.

, (2005) Romance del duende que me escribe las novelas, Santiago: Planeta.

, (2006) El fantasista, Santiago: Alfaguara.

, (2009) La contadora de películas, Santiago: Alfaguara.

, (2013) Historia de amor con hombre bailando, Santiago: Alfaguara.

, (2014) El vendedor de pájaros, Santiago: Alfaguara.

\section{BIBLIOGRAFÍA DE REFERENCIA}

Castañeda Hernández, María del Carmen, Hipertexto y carnaval: El arte de la resurrección de Rivera Letelier, disponible en http://www.omnibus.com/n42/sites.google.com/site/omnibusrevistainterculturaln42/literatura/ hipertexto-y-carnaval.html

Flores, Jorge, La Muerte es una Vieja Historia: Hernán Rivera Letelier, disponible en http://escribidores.bligoo.cl/hernan-rivera-letelier-la-muertes-es-unavieja-historia

García, Javier, Hernán Rivera Letelier: "Me faltaba contar una historia donde ellas fueran las heroínas", disponible en http://www.latercera.com/noticia/cultura/2014/06/1453-581564-9-hernanrivera-letelier-me-faltaba-contar-una-historia-donde-ellas-fueran-las.shtml

\section{(ब) $\odot \odot$}

La Revista Estudios es editada por la Universidad de Costa Rica y se distribuye bajo una Licencia Creative Commons Atribución-NoComercial-CompartirIgual 3.0 Costa Rica. Para más información envíe un mensaje a revistaestudios.eeg@ucr.ac.cr. 
Especial: Naturaleza amena y naturaleza agreste en las letras hispánicas

Gatica, Jaime, Los trenes se van al purgatorio, disponible en https://es.scribd.com/doc/123515649/Los-Trenes-Se-Van-Al-Purgatorio

Gómez, Andrés, Hernán Rivera Letelier: "Yo no puedo escribir modas; todo me nace de las vísceras", disponible en $\quad$ http://diario.latercera.com/2015/03/07/01/contenido/culturaentretencion/30-184972-9-hernan-rivera-letelier-yo-no-puedo-escribir-pormodas-todo-me-nace-de-las.shtml

Maíz, Claudio. 2002. "La narrativa de Rivera Letelier. Los signos de la escasez y la abundancia compensatoria" en Revista Universum núm. 17. Universidad de Talca.

Ostria, Mauricio. 2014. "Poéticas del desierto: dos voces" en Nueva revista de Pacífico, núm. 60.

Promis, José, Talento de narrador, disponible en $\quad$ http://www.elmercurio.com/blogs/2014/08/03/24057/Talento-denarrador.aspx

SABELLA, Andrés, ([1944] 1956). Norte Grande. Novela del salitre. Santiago. Ediciones Orbe.

Notas:

Datos tomados de las $\quad$ siguientes fuentes:
/www.biografiasyvidas.com/biografia/r/rivera_letelier.htm, así como /www.escritores.org >
Biografías

ii Dato biográfico narrado en Himno del ángel parado en una sola pata (1996). Cfr. cap. 4. La narrativa de este autor presenta una constante base biográfica.

iii “La Sociedad Química y Minera de Chile (SOQUIMICH) fue creada el año 1968 como parte de un plan de reorganizar la industria del salitre. Estaba constituida por la Unión de la Corporación de Ventas de Salitre y Yodo, Compañía Anglo Lautaro, Compañía Victoria y el Estado de manera que Anglo Lautaro quedó con un 62,5\% de participación, mientras que el 37,5\% restante quedó en manos de la Corporación de Fomento de la Producción,

\section{(c) (i) (2) (2)}

La Revista Estudios es editada por la Universidad de Costa Rica y se distribuye bajo una Licencia Creative Commons Atribución-NoComercial-Compartirlgual 3.0 Costa Rica. Para más información envíe un mensaje a 
Especial: Naturaleza amena y naturaleza agreste en las letras hispánicas

CORFO). El objetivo de SOQUIMICH se centró en reapertura de yacimientos de salitre (materia prima para la elaboración de fertilizantes y explosivos) y yodo. En el año 1971, el Estado de Chile por medio de la CORFO adquiere el $100 \%$ de la propiedad de SOQUIMICH y, por lo tanto, se nacionaliza la explotación del salitre. A partir de 1995 ha sido foco mediático por fraudes, escándalos financieros y evasión fiscal". Cfr. Edmundo Polanco Valenzuela, "Historia de SOQUIMICH, una revisión" p. 2, trabajo leído en Congreso XIV Congreso Geológico Chileno, La Serena, octubre de 2015, hospedado en www.sernageomin.cl/pdf/congresogeo/37.pdf.

iv “En el año 1981 una cláusula del nuevo Código Minero le otorgó a tanto a CORFO como a SOQUIMICH seis meses de exclusividad para realizar manifestaciones mineras. El sentido era asegurar que el Estado se transformará en el dueño de los yacimientos conocidos. El resultado fue que SOQUIMICH acaparó más de 93 mil hectáreas de terreno con los mejores yacimientos de yodo y salitre, incluidos Pedro de Valdivia y María Elena (90\% del salitre y yodo es de su propiedad El proceso de privatización de SOQUIMICH se enmarca en una política nacional de la dictadura militar de traspasar a manos privadas las empresas del Estado. En particular, en el año 1979 SOQUIMICH era una de las muchas empresas del Estado que no sólo no generaba utilidades sino que daba origen a pérdidas económicas (más de 20 millones de dólares al año). Esta situación, obliga a la urgente intervención con la idea de modernizar esta empresa. En este contexto, es nombrado Director de SOQUIMICH, entre otros cargos públicos, Julio Ponce Lerou, en ese entonces yerno de Pinochet. No obstante, al poco tiempo se retira de la vida pública por un bullado caso de enriquecimiento ilícito. Esta ausencia de Ponce que se extiende entre los años 1983 y 1987 coincide en gran parte con la materialización del proceso de privatización de la empresa (1983-1989). Este proceso incluyó la creación en el año 1986 de Pampa Calichera que se transformó en uno de los dueños de SOQUIMICH y la instauración de lo que llamó "capitalismo popular" con la participación de los trabajadores como dueños de un $4,2 \%$ del paquete accionario de la empresa". Cfr. Edmundo Polanco Valenzuela, Op. cit., p. 2

${ }^{\vee}$ Me refiero a La muerte es una vieja historia, Santiago, Alfaguara, 2015; La muerte tiene olor a Pachulí, Santiago, Alfaguara, 2016 y La muerte se desnuda en La Habana, 2017.

vi Boris Tomashevski, "La construcción de la trama", en Teoría de la literatura, Madrid, Akal, 1982.

vii El desierto de Atacama, el desierto no-polar más árido de la Tierra, se extiende en el Norte Grande de Chile - abarcando las regiones de Arica, Parinacota, Tarapacá, Antofagasta, Atacama y el norte de la región de Coquimbo -y cubre una superficie de aproximadamente $105000 \mathrm{~km}^{2}$. Tiene una longitud de casi $1600 \mathrm{~km}$ y un ancho máximo de $180 \mathrm{~km}$. Es de tipo costero frío y está delimitado por el océano Pacífico al oeste y por la cordillera de los Andes al este.

viii La oficina salitrera S. Humberstone —que en su época de auge albergó a 3500 habitantes- y Santa Laura, que en su esplendor llegó a 450 habitantes, dos

La Revista Estudios es editada por la Universidad de Costa Rica y se distribuye bajo una Licencia Creative Commons Atribución-NoComercial-CompartirIgual 3.0 Costa Rica. Para más información envíe un mensaje a revistaestudios.eeg@ucr.ac.cr. 
Especial: Naturaleza amena y naturaleza agreste en las letras hispánicas

antiguas oficinas salitreras, actualmente son las más conocidas y funcionan como museo; están administradas por la Corporación Museo del Salitre y fueron declaradas Monumentos Nacionales y Patrimonio Cultural de la Humanidad. Tomado de www.bbc.com/mundo/noticias/2015/02/150205_cultura_chile_historia_humberstone_finde _ng. Cfr. también La vida cotidiana en la pampa salitrera (1830-1930) - Memoria Chilena en www.memoriachilena.cl/602/w3-article-3548.htm y La industria salitrera (1880-1930) Memoria Chilena, Biblioteca en www.memoriachilena.cl/602/w3-article-3309.html

${ }^{i x}$ Cfr. Julio Ortega. 2010. La imaginación crítica. Santiago: Ediciones Universidad Alberto Hurtado, Cap. "Narrativa hispanoamericana: para un modelo crítico".

ix Cfr., Tetsuro Watsuji. (2006) Antropología del paisaje. Climas, culturas y religiones. Salamanca, Ediciones Sígueme.

La Revista Estudios es editada por la Universidad de Costa Rica y se distribuye bajo una Licencia Creative Commons Atribución-NoComercial-CompartirIgual 3.0 Costa Rica. Para más información envíe un mensaje a revistaestudios.eeg@ucr.ac.cr. 